\section{Pecan Fruit Shuck Thickness is Related to Nut Quality}

T.E. Thompson ${ }^{1}$

Agricultural Research Service, U.S. Department of Agriculture, College Station, TX 77840

Additional index words. Carya illinoinensis, breeding, genetics, nut quality

Abstract. Pecan [Carya illinoinensis (Wangenh.) K. Koch] fruit presents a considerable weight for the tree to support during the growing season. A major part of this weight is due to the pecan shuck that surrounds the developing nut and kernel. Pecan clones vary considerably for the amount of shuck per nut, and little is known as to the value of this weight in determining final nut quality. Six cultivars differing in basic nut shapes and sizes were studied and found to vary greatly for shuck thickness, and weight of shuck per unit final nut weight and volume. Shuck thickness was shown to be a favorable genetic characteristic since fruit with thicker shucks had slightly greater nut fresh and dry weight, nut volume, nut density, kernel weight and content, and shuck weight per nut volume. 'Sioux' had the thickest shucks $(4.70 \mathrm{~mm})$, while 'Pawnee' had the thinnest shucks $(3.72$ $\mathrm{mm})$. Fresh weight per fruit varied from $21.25 \mathrm{~g}$ for 'Podsednik' to $10.18 \mathrm{~g}$ for Osage. Weight of fruit per tree was extrapolated using average shuck and nut weights, and it was determined that the fruit on each tree would weigh about $104 \mathrm{~kg}$. This is a considerable weight, and adds substantially to limb breakage. However, thicker shucks contribute to final nut quality.

The fruit of pecan (Carya illinoinensis (Wangenh.) K. Koch) can be divided into three parts: shuck (involucre), shell, and kernel (Thor and Smith, 1935, 1939; Woodroof, 1927). The various functions of the shuck in relation to nut development and final nut quality have been of interest to pecan scientists for years. Shucks constitute a major source of fruit weight that contributes to limb breakage during wind storms. Conversely, we know that all nutrition to the developing kernel is routed through the vascular system of the shuck (Calcote et al., 1984). Shuck thickness in relation to insect resistance may also be a factor for some insects, but probably not for shuckworm (Laspeyresia caryana (Fitch). Calcote et al. (1976) studied shuck thickness in relation to shuckworm damage and found these to be unrelated.

Determining whether kernel percentage, nut density, or other parameters are the main indicators of nut quality has been debated for years (Romberg, 1952; Smith, et al., 1948; Thompson, et al., 1989). Kernel percentage is certainly important, and is used throughout the industry to determine price per unit weight of pecans in shell. Beyond this, the final weight of the kernel half or piece after shelling is important, producing a premium for large halves or pieces. In this research, we use percentage of kernel, kernel weight, as well as other factors to measure nut quality.

In the U.S. Department of Agriculture pecan breeding program (Grauke and Thompson, 1996; Thompson and Grauke, 1991), we need to determine if greater shuck thickness is a desirable genetic trait, or a liability in producing orchards. Especially as higher yielding clones are developed, will the added fruit weight be a limiting factor and make trees

Received for publication 7 Feb. 2005. Accepted for publication 20 Mar. 2005.

${ }^{1}$ Research geneticist. much more susceptible to limb breakage during wind storms? On the other hand, if thickness contributes adequately to kernel nutrition and final kernel quality, the added weight may be justifiable.

\section{Materials and Methods}

Pecan fruit samples were collected from six clones in a replicated cultivar performance orchard at Brownwood, Texas. This test was begun in 1981 when 3-year-old bare-root 'Apache' rootstocks, grown from open-pollinated seed, were planted in a nearly level DeLeon silty clay soil (Fine, mixed, thermic Udertic Haplustolls). Trees were spaced 10.7 $\mathrm{m}$ each way, in a square design, with 87.8 trees per ha. Single tree plots with four blocks were grafted in April 1986. State extension orchard care recommendations for this locale were followed.

Cultivars were selected to represent a range of nut sizes, shapes, and nut maturity dates. Nut shapes (Table 1) are based on our standard nut shape classification system used as a descriptor in the breeding program and in our National Clonal Germplasm Repository for Pecans and Hickories. This system has seven nut shape classes. Shape classification is based on nut length to height ratios, where height is measured as the widest point perpendicular to the plane of the suture: orbicular $=1$ to 1.39 ; shuck parameters and other fruit traits. ovate $=1.40$ to 1.59 , widest at base; obovate $=1.40$ to 1.59 , widest at apex; oval elliptic $=$ 1.40 to 1.59 , widest in middle; elliptic $=1.60$ to 1.79 ; oblong elliptic $=1.80$ to 1.99 ; and oblong $=>2.00$ ). 'Podsednik' has the largest nut of any known pecan clone, while 'Sioux' and 'Osage' produce small nuts. 'Mahan' is a large long nut while 'Podsednik' is a blocky nut. 'Osage' and 'Pawnee' are early maturing cultivars, while 'Sioux' is late.

Four replications (single trees) were sampled. Twenty fruit from each tree were collected at about $2.5 \mathrm{~m}$ from the ground and from all sides of the trees from each of six cultivars. The nuts were harvested when mature enough to completely separate from the shuck. Complete fruit (nuts still in shucks) were removed from trees and transferred to the lab and individually measured (Table 2). Data collected or computed included shuck fresh weight, shuck dry weight, shuck percent dry weight, shuck thickness on suture, shuck thickness off suture, shuck thickness mean, nut fresh weight, nut dry weight, nut percent dry weight, nut length, nut width across suture, nut height perpendicular to suture, nut buoyancy, nut volume, nut density, kernel weight, kernel content, and shuck weight per nut volume. Shuck percent dry weight was computed by dividing shuck dry weight by shuck fresh weight. Shuck thickness on the suture was determined by cutting through the shuck transverse to the suture and measuring thickness with calipers. This measurement was repeated for the opposite shuck position and measurements averaged. Shuck thickness off the suture was determined by a similar measurement ninety degrees from first measurement. Shuck thickness mean was the average of these four measurements. Nut percent dry weight was determined by dividing the nut dry weight by the nut fresh weight.

Nut buoyancy was determined by submerging individual nuts in a weighted screen container in water below a digital balance (modified method described by Waugh, (1938)). The balance was supported by a wooden frame above a container of water. The difference in weight of the empty screen container suspended in the water and the decreased weight of the container with the nut submerged was buoyancy. Buoyancy in grams was added to nut weight to determine nut volume in milliliters since density of water is 1.0. Nut density was determined by diving weight by volume.

Nuts were then individually shelled and kernel content (expressed as a percent of the nut weight) was determined. Shuck weight per nut volume was determined by dividing the fresh shuck weight by nut volume to give an estimate

Table 1. Parentage, nut shape classification, and sample collection dates for pecan clones measured for

\begin{tabular}{|c|c|c|c|c|}
\hline Cultivar & $\begin{array}{c}\text { Female } \\
\text { parent }\end{array}$ & $\begin{array}{c}\text { Male } \\
\text { parent }\end{array}$ & $\begin{array}{l}\text { Nut } \\
\text { shape }\end{array}$ & $\begin{array}{c}\text { Fruit collection } \\
\text { date (1997) }\end{array}$ \\
\hline Mahan & Unknown & Unknown & Oblong & 14 Oct. \\
\hline Osage & Major & Evers & Oval elliptic & 17 Sept. \\
\hline Pawnee & Mohawk & Starking Hardy Giant & Oblong elliptic & 22-26 Sept. \\
\hline Podsednik & Unknown & Unknown & Elliptic & 17-30 Oct. \\
\hline Sioux & Schley & Carmichael & Oblong & 23 Oct. \\
\hline Wichita & Halbert & Mahan & Oblong & 7-9 Oct. \\
\hline
\end{tabular}


Table 2. Shuck and nut measurements for pecan fruit. Means in rows are compared using Duncan's multiple range test $(p=0.05)$.

\begin{tabular}{lrrrrrrr}
\hline Fruit measurement & Mahan & Osage & Pawnee & Podsednik & Sioux & Wichita & Mean \\
\hline Shuck fresh weight (g/fruit) & $16.08 \mathrm{c}$ & $10.18 \mathrm{e}$ & $13.76 \mathrm{~d}$ & $21.25 \mathrm{a}$ & $15.85 \mathrm{c}$ & $17.25 \mathrm{~b}$ & 15.60 \\
Shuck dry weight (g/fruit) & $2.65 \mathrm{c}$ & $1.88 \mathrm{f}$ & $2.18 \mathrm{e}$ & $3.50 \mathrm{a}$ & $2.44 \mathrm{~d}$ & $3.09 \mathrm{~b}$ & 2.60 \\
Shuck \% dry weight (\%) & $0.17 \mathrm{~b}$ & $0.18 \mathrm{a}$ & $0.16 \mathrm{bc}$ & $0.17 \mathrm{~b}$ & $0.16 \mathrm{c}$ & $0.19 \mathrm{a}$ & 0.17 \\
Shuck thickness on suture (mm) & $3.92 \mathrm{c}$ & $3.99 \mathrm{c}$ & $3.70 \mathrm{~d}$ & $4.61 \mathrm{a}$ & $4.50 \mathrm{ab}$ & $4.40 \mathrm{~b}$ & 4.19 \\
Shuck thickness off suture (mm) & $4.09 \mathrm{~d}$ & $3.75 \mathrm{e}$ & $3.75 \mathrm{e}$ & $4.30 \mathrm{c}$ & $4.91 \mathrm{a}$ & $4.54 \mathrm{~b}$ & 4.23 \\
Shuck thickness mean (mm) & $4.00 \mathrm{c}$ & $3.87 \mathrm{~cd}$ & $3.72 \mathrm{~d}$ & $4.45 \mathrm{~b}$ & $4.70 \mathrm{a}$ & $4.47 \mathrm{~b}$ & 4.21 \\
Nut fresh weight (g/nut) & $9.21 \mathrm{c}$ & $6.45 \mathrm{f}$ & $8.66 \mathrm{~d}$ & $17.02 \mathrm{a}$ & $7.91 \mathrm{e}$ & $10.19 \mathrm{~b}$ & 9.80 \\
Nut dry weight (g) & $4.18 \mathrm{e}$ & $4.14 \mathrm{e}$ & $5.05 \mathrm{~d}$ & $7.99 \mathrm{a}$ & $5.47 \mathrm{c}$ & $7.06 \mathrm{~b}$ & 5.67 \\
Nut percent dry weight (\%) & $0.45 \mathrm{~d}$ & $0.64 \mathrm{~b}$ & $0.58 \mathrm{c}$ & $0.47 \mathrm{~d}$ & $0.69 \mathrm{a}$ & $0.69 \mathrm{a}$ & 0.60 \\
Nut length (mm) & $54.33 \mathrm{a}$ & $30.82 \mathrm{e}$ & $41.91 \mathrm{~d}$ & $49.54 \mathrm{~b}$ & $41.20 \mathrm{~d}$ & $45.66 \mathrm{c}$ & 43.34 \\
Nut width (mm) & $22.60 \mathrm{~b}$ & $20.30 \mathrm{c}$ & $20.12 \mathrm{c}$ & $29.30 \mathrm{a}$ & $19.71 \mathrm{~d}$ & $22.42 \mathrm{~b}$ & 22.26 \\
Nut height (mm) & $22.48 \mathrm{~b}$ & $21.26 \mathrm{c}$ & $22.62 \mathrm{~b}$ & $29.46 \mathrm{a}$ & $19.97 \mathrm{~d}$ & $21.20 \mathrm{c}$ & 22.72 \\
Nut buoyancy (g) & $7.57 \mathrm{~b}$ & $1.53 \mathrm{e}$ & $3.25 \mathrm{c}$ & $8.18 \mathrm{a}$ & $1.59 \mathrm{e}$ & $2.32 \mathrm{~d}$ & 3.84 \\
Nut volume (mL) & $11.74 \mathrm{~b}$ & $5.67 \mathrm{f}$ & $8.30 \mathrm{~d}$ & $16.18 \mathrm{a}$ & $7.06 \mathrm{e}$ & $9.38 \mathrm{c}$ & 9.50 \\
Nut density $\left(\mathrm{g} \cdot \mathrm{mL} \mathrm{C}^{-1}\right)$ & $0.36 \mathrm{e}$ & $0.74 \mathrm{~b}$ & $0.61 \mathrm{c}$ & $0.49 \mathrm{~d}$ & $0.78 \mathrm{a}$ & $0.75 \mathrm{ab}$ & 0.63 \\
Kernel weight $(\mathrm{g})$ & $1.30 \mathrm{~d}$ & $2.09 \mathrm{c}$ & $2.29 \mathrm{c}$ & $3.31 \mathrm{~b}$ & $3.12 \mathrm{~b}$ & $4.17 \mathrm{a}$ & 2.77 \\
Kernel content $(\%)$ & $30.4 \mathrm{e}$ & $50.2 \mathrm{~b}$ & $44.2 \mathrm{c}$ & $39.8 \mathrm{~d}$ & $56.8 \mathrm{a}$ & $58.3 \mathrm{a}$ & 47.5 \\
Shuck weight per nut volume $\left(\mathrm{g} \cdot \mathrm{mL}^{-1}\right)$ & $1.37 \mathrm{~d}$ & $1.80 \mathrm{~b}$ & $1.66 \mathrm{c}$ & $1.30 \mathrm{~d}$ & $2.24 \mathrm{a}$ & $1.83 \mathrm{~b}$ & 1.72 \\
\hline
\end{tabular}

of relative amount of shuck per nut.

The General Linear Models (GLM) procedures of the Statistical Analysis System (SAS Institute, Cary, N.C.) were used to determine the influence of clones and other factors upon shuck and nut measurements. Duncan's multiple range tests were used to separate means.

\section{Results and Discussion}

Shuck, nut, and kernel characteristics varied greatly (Table 2). 'Podsednik' produces the largest fruit of any pecan cultivar. 'Osage' is a small early-maturing cultivar. Shuck percent dry weight varied little, but was more consistent within each cultivar. Shuck thickness on the suture was thickest on 'Podsednik', 'Sioux', and 'Wichita', and therefore was not related to nut size. An interesting concept is that as nut size increases, the surface area or shuck area per unit nut or kernel weight decreases since pecans are near spherical objects. Also, the surface area per unit weight increases as the nut length increases, presuming that nut size is the same. An unproven premise in pecan is that smaller nuts fill better, or produce smaller but better developed kernels. Shuck thickness off the suture (but not on the suture), and shuck thickness mean was the greatest for 'Sioux', both greater than for 'Podsednik'. Nut fresh and dry weights were much greater for 'Podsednik', while nut percent dry weight for 'Sioux' was greatest. Perhaps this greater shuck weight per unit kernel weight contributes to the reputation that 'Sioux' has in the market of producing more consistent quality than many of the larger cultivars.

Nut shape varied greatly, with 'Mahan' being the longest nut (Table 2). This shape would mathematically mean more shuck surface area compared to orbicular shaped nuts. Across all cultivars, nut width on and off the suture varied little, but diverged the most for 'Pawnee'. Nut buoyancy was greatest for the largest nuts, 'Podsednik' and 'Mahan', as expected, making nut volume vary the same, and largely resulting in low densities for these two cultivars. Kernel weights were very low for 'Mahan', resulting in a low percent kernel, while 'Podsednik' had much more kernel and a much better percent kernel, as did the other cultivars.

Shuck weight per nut volume may be the most direct test to determine the importance of the shuck in determining nut quality $(r=$ $0.65)$ (Table 3). It varied greatly, with 'Sioux' exceeding the other cultivars (Table 2). Correlation values were significant for this measurement across all six cultivars (Table 3 ). This reinforces the premise that shucks play a major role in determining final nut quality since this cultivar traditionally is such a fine quality nut in the market.

As expected, shuck thickness on and off the suture were strongly correlated (Table 3 ), and for most purposes, the mean reflects accurately both of these measurements. The one possible exception is nut width off the suture which was unrelated to shuck width off the suture, but positively related to shuck width on the suture. It may be that as nut development occurs, this area of shuck is stretched to accommodate nut development more than the other plane of the nut.

Mean shuck thickness was, as expected, strongly correlated with shuck fresh weight and shuck dry weight, but negatively related to shuck percent dry weight. This may be due to decreasing shuck thickness as it dries. The individual nuts and shucks from the same fruit obviously dried together, and this is shown by the significant but low $r$ value of 0.093 for shuck and nut percent dry weight. The other negative associations of shuck percent dry weight with nut fresh and dry weight, nut length, and nut volume is not completely understood. The significant negative association between shuck percent dry weight and shuck weight per unit nut volume is possibly due to the drier shucks weighing less.

Nut fresh and dry weights were positively associated with many parameters of nut size (nut length, width on and off suture, volume, and kernel weight). Nut fresh weight was

Table 3. Pearson correlation values (r) for pecan nut and fruit characteristics. Values that are significant at any level $(P<0.05,0.01$, or 0.001$)$ are in bold type.

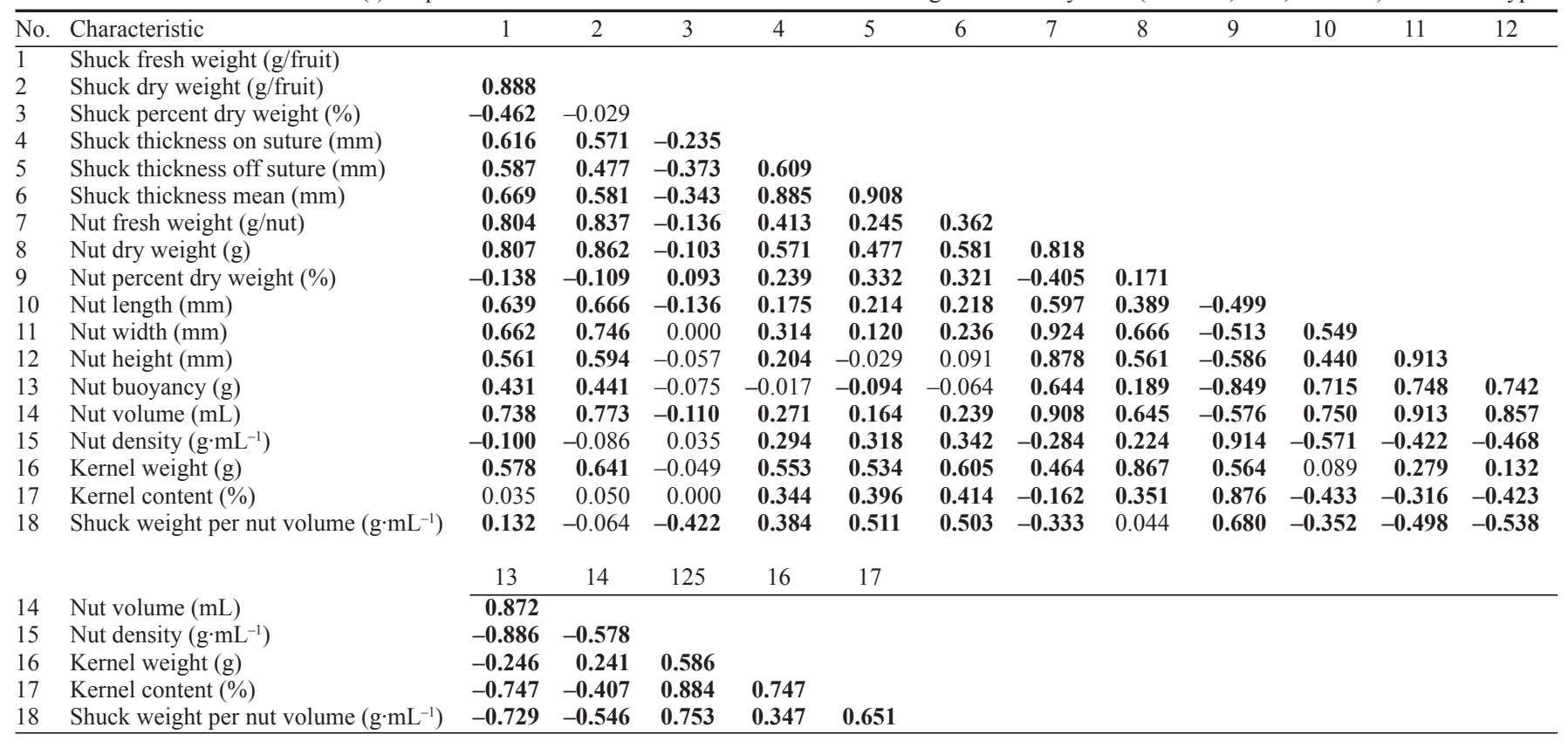


Table 4. Pearson correlation coefficients $(r)$ and level of statistical significance for percent kernel as related to shuck thickness measurements for pecan cultivars.

\begin{tabular}{lcccccc}
\hline Measurement & Mahan & Osage & Pawnee & Podsednik & Sioux & Wichita \\
\hline Shuck thickness on suture $(\mathrm{mm})$ & 0.41 & 0.300 & 0.59 & 0.41 & 0.31 & 0.18 \\
& 0.001 & 0.006 & 0.000 & 0.000 & 0.005 & 0.118 \\
Shuck thickness off suture $(\mathrm{mm})$ & 0.37 & 0.06 & 0.57 & 0.38 & 0.29 & 0.35 \\
& 0.003 & 0.613 & 0.000 & 0.001 & 0.008 & 0.001 \\
Shuck thickness mean $(\mathrm{mm})$ & 0.44 & 0.22 & 0.62 & 0.46 & 0.35 & 0.30 \\
& 0.000 & 0.050 & 0.000 & 0.000 & 0.002 & 0.006 \\
\hline
\end{tabular}

negatively related to nut percent dry weight as expected since the nut looses weight as it dries. Nut buoyancy increased as nut fresh and dry weight increased. On a unit basis, this is expected, but it may indicate that larger nuts are relatively more difficult to develop into well-filled nuts. That nut density and percent kernel are negatively related to nut size further verifies results from earlier studies (Thompson, etal., 1989). Nut volume was negatively related to nut percent dry weight.

Overall, percent kernel was positively correlated with shuck thickness above the nut suture, opposite the suture, and of course, the average of these two (Table 3). However, there were some interesting interactions within clones (Table 4). All of these correlations were significant except the off suture measurement for 'Osage', and the on suture measurement for 'Wichita'. Mean thicknesses for 'Osage' and 'Wichita' were significant.

There are at least two possible reasons why percent kernel is related to shuck thickness. One is that thicker shucks are more efficient in nurturing developing kernels by producing and supplying nutrients. This would mean that thicker shucks are more efficient photosynthetically, or more efficient in transporting nutrients to the developing kernel, or some other reason. The importance of shucks as photosynthesizing structures may sometimes be underestimated in pecan science. A second possible explanation as to why fruit with thicker shucks have

of the entire fruit. That is, both shucks and kernels may be more adequately developed due to greater leaf area per fruit, fewer nuts per cluster, or other factors that contribute to more desirable general fruit nutrition. This would mean that thicker, more developed shucks and better developed kernels both resulted from better general nutrition, and that the latter is not the result of the former. In any event, they are related, and selection for thicker shucks in the breeding program should be an effective strategy to improve kernel quality.

The weight of the fruit on a pecan tree is substantial. For instance if the mean shuck fresh weight of $15.6 \mathrm{~g}$ (Table 2) and the fresh nut weight $(9.8 \mathrm{~g})$ are added, we get $25.4 \mathrm{~g}$. per fruit. In a common pecan orchard having 86.4 trees per ha, and yielding $2,000 \mathrm{~kg} \cdot \mathrm{ha}^{-1}$ of dry nuts weighing $5.67 \mathrm{~g}$ each, this would equal 4,083 fruit per tree, and about $104 \mathrm{~kg}$ of fruit weight per tree. This weight can be considered minimal since values from this study were used and some drying and weight decreases had occurred before fruit were harvested.

Overall, shuck thickness is shown to be a desirable genetic characteristic due to its general positive effect on percent kernel. The considerable weight that thicker shucks add to the weight that a tree must support during the growing season is justifiable since it contributes to final nut quality. These results show the importance of the shuck in nut development, and are consistent with our earlier work verifying that all nut nutrition is routed through the vascular system of the shuck.

\section{Literature Cited}

Calcote, V.R., R.E. Hunter, and T.E. Thompson. 1984. Nutrient flow through the pecan shuck into the nut and disruption of this flow by hickory shuckworm larvae. Proc. SE Pecan Growers Assn. 77:61-69.

Calcote, V.R., G.D. Madden, and H.D. Peterson. 1976. Pecan cultivars resistant to hickory shuckworm. Proc. N. Nut Growers Assn. 67:19-21.
Grauke, L.J. and T.E. Thompson. 1996. Pecans and hickories, p. 185-239. In: J.A. Janick and J.N. Moore (eds.). Fruit breeding. vol. 3. Nuts. Wiley and Sons, Inc., New York.

Romberg, L.D. 1952. Measurement of the filling of pecan nuts. Texas Pecan Growers Assn. 31:35-42.

Smith, C.L., J. Hamilton, and L.D. Romberg. 1948. Specific gravity and percentage of kernel as criteria of filling of pecan nuts. Proc. Amer. Soc. Hort. Sci. 51:157-170.

Thompson, T.E. and L.J. Grauke. 1991. Pecans and other hickories (Carya), p. 839-904. In: J.N. Moore and J.R. Ballington (eds.). Genetic resources of temperate fruit and nut crops. Intl. Soc. Hort. Sci., Wageningen.

Thompson, T.E., E.F. Young, Jr., W.O. McIlrath, H.D. Petersen, and G.S. Sibbett. 1989. Pecan nut and kernel characteristics show genotypeenvironment interactions. J. Amer. Soc. Hort. Sci. 114:706-711.

Thor, C.J.B. and C.L. Smith. 1935. A physiological study of seasonal changes in the composition of the pecan during fruit development. J. Agr. Res. 50(2):97-121.

Thor, C.J.B. and C.L. Smith. 1939. A physiological study of the prefilling period of fruit development in the pecan. J. Agr. Res. 58(12):905-910.

Woodroof, J.G. 1927. The development of the pecan nut (Hicoria pecan) from flower to maturity. J. Agr. Res. 34(11):1049-1063.

Waugh, J.G. 1938. Approximate specific gravity determination, a rapid method for use with pecans and similar small objects. Ind. Eng. Chem. 10:209-211. 